\title{
COMPREHENDING THE TOPIC OF A PARAGRAPH: A FUnCtional IMAGING STUDY OF A COMPLEX LANGUAGE PROCESS
}

(Compreendendo o tópico de um parágrafo: Um estudo de neuroimagem funcional sobre um processo lingüístico complexo)

\author{
Lêda Maria Braga ToмiтcH \\ (Universidade Federal de Santa Catarina)
}

Sharlene D. NEwMAN

(Indiana University-EUA)

Patricia A. Carpenter and Marcel Adam Just

(Carnegie Mellon University-EUA)

\begin{abstract}
This study uses FMRI (functional magnetic resonance imaging) to investigate the brain activity in a set of cortical a reas in the task of main idea identification, when the topic sentence was presented in first versus in last position in a three-sentence paragraph. The participants were eight right-handed undergraduate students from Carnegie Mellon University, six male and 2 female, all native speakers of English. Each participant read twelve paragraphs, six in which the topic sentence was paragraph initial and six in which it was paragraph final, and each paragraph was presented word by word in the center of a screen, inside the scanner. The major finding of the current study is the differential response observed in the left and right hemispheres as to the location of the topic sentence within the paragraph. The left temporal region showed greater activation when the topic sentence was in final position than in initial position. The right temporal region, on the other hand, was affected only by sentence type, showing a greater response to topic sentences than support sentences, regardless of their location within the paragraph.
\end{abstract} KEY-WORDS: FMRI; Main idea identification; Discourse processing.

RESUMO: Este estudo utiliza a ressonância magnética funcional para investigar a atividade cerebral em áreas corticais durante a execução da tarefa de extração de idéias principais, quando a idéia principal é apresentada no início ou ao final de um parágrafo com três orações. Os participantes da pesquisa foram oito alunos de graduação da Universidade de Carnegie Mellon, todos destros, falantes nativos do inglês. Cada participante leu doze parágrafos, seis com a idéia principal no início e seis com a idéia principal no final do parágrafo, e cada parágrafo foi apresentado palavra por palavra, 
no centro de uma tela, dentro do aparelho de ressonância magnética. O maior achado do presente estudo refere-se à resposta diferenciada observada nos hemisférios direito e esquerdo. A região temporal esquerda mostrou maior atividade cerebral quando a idéia principal era apresentada em posição final do que em posição inicial. A região temporal direita, por sua vez, só foi afetada pelo tipo de oração, mostrando uma maior atividade durante o processamento da idéia principal do que das idéias secundárias, independente da sua posição no parágrafo, inicial ou final.

PALAVRAS-CHAVE: Ressonância magnética funcional; Identificação de idéias principais; Processamento textual.

\section{Introduction}

Main idea identification is at the very heart of human thinking, being a skill required in everyday situations such as reading a message, interpreting an interlocutor's utterance, listening to the news and attending a lecture. It is part of human nature to try to integrate incoming information or build a macrostructure containing the main points of the input, so that this information can be more easily stored in memory, related to other knowledge, and retrieved when needed (Kintsch \& van Dijk 1978; van Dijk \& Kintsch 1983). Despite its importance in human interaction, the process of main idea identification is little understood. Here, a text comprehension task is used to explore the process of identifying the main idea, or topic of a text.

Cognitive brain imaging has provided researchers new possibilities for trying to understand what happens in the human brain during the performance of various complex tasks. While there is an extensive neuroimaging literature investigating comprehension processes at the word level (e.g. Petersen et al 1989,1990; Pugh et al 1996, 2000; Binder 1997; Fiez \& Petersen 1998; Brunswick et al 1999; Hagoort et al 1999; Shaywitz et al 2000; Waldie \& Mosley 2000), and sentence level (Mazoyer et al 1993; Bottini et al 1994, Just et al 1996; Stromswold et al 1996; Bavelier et al 1997; Schlosser et al 1998; Caplan et al 1999; Keller et al 2001; and Michael et al 2001), there are few neuroimaging studies that have gone beyond the sentence level and examined discourse comprehension (Mazoyer 
et al 1993; Nichelli et al 1995; Dehaene et al 1997; St George et al. 1999; Robertson et al 2000; Mason \& Just 2004; Tomitch, Newman \& Just 2004). Lesion studies, however, have provided some insight into the underlying neural architecture that supports discourse comprehension. It has been found that patients with right hemisphere damage often experience difficulties at the discourse level even though their ability to comprehend at the word and sentence level are intact. For example, right hemisphere patients often have problems maintaining the theme of discourse (Brownell \& Martino 1998), suggesting that the right hemisphere is responsible for main idea identification and maintenance.

The current study examines main idea identification by examining the effect of the position of the topic sentence in three-sentence paragraphs. There were two conditions that differed in the position of the main idea/ topic sentence in the paragraph: in first position - topic first and in last position- topic last. The topic sentence contained a superordinate theme that unified the concepts in the other sentences. The placement of the topic sentence dramatically affects how the coherence of the discourse is established and therefore, the ease at which the text is comprehended. The experimental design was intended to contrast the processes of integrating text details into a previously established theme, versus first storing details or dynamically integrating them prior to reading the statement of the topic, and then relating them to the topic.

Computational models have been proven to be very important in understanding cognition. As such, the Structure Building Framework (SBF) of Gernsbacher $(1990,1995,1997)$ is used here to frame the current study and to guide its interpretation. SBF can account for several phenomena (e.g., the advantage of the first mention and the clause recency effect) related to the comprehension processes that establish text coherence. According to the SBF, discourse comprehension builds cohesive mental representations using three general processes: laying the foundation of a text representation, mapping incoming information from the text to previous information, and initiating a new substructure if the incoming information is not adequately coherent with previous information. SBF states that the first step in building a mental representation of the text is to lay a foundation to which subsequent information presented in the text can be attached. Laying a foundation presumably consists of selecting or 
constructing an organizing structure or schema for the text. Once the foundation has been built, the structure is then elaborated by mapping incoming information to the schema and shifting to develop new substructures when needed. SBF can be used to make several predictions regarding the results of the current study. SBF states that attempts to lay the foundation begin with the first phrase of the first sentence, regardless of the content of that phrase. Therefore, SBF would predict that the initiation of this content-free foundation formation process has no preference as to which sentence type comes first, either topic or support sentence. Also, according to SBF, in the topic last condition the topic of the text is available after the initiation of foundation formation. Therefore, a second prediction is that more substructures may be expected to be generated during the topic last condition compared to the topic first condition which indicates more "shifting" processing. This suggests that the increase in shifting is expected to result in a higher level of activation for the topic sentence when it is in the final position compared to when it is located in the initial position. This also suggests that the text representation generated when the topic is last is more complex and may be more memory intensive.

SBF is a psychological model of discourse processing and therefore, does not address the neural basis of text comprehension. One neural-based hypothesis concerning comprehension that does relate to discourse processing is the coarse coding hypothesis proposed by Beeman (1993; 1998; Beeman et al 1994). The coarse coding hypothesis proposes that the two hemispheres differ in the comprehensiveness of the representations they activate. According to this hypothesis, the left hemisphere uses fine (precise) semantic coding to selectively activate a small number of relevant meanings or features when processing language. The right hemisphere, on the other hand, is proposed to use a coarse semantic coding scheme in which it weakly activates a broad spectrum of related meanings and features, inducing diffusely activated semantic fields distributed over many representations. This type of coding scheme is thought to support inference generation, which is often necessary to connect events within a passage.

The goal of the current study is to attempt to characterize the neural architecture that supports discourse processing, particularly topic identification. This was done by using fMRI to examine paragraphs that varied the location of the topic sentence. 


\section{Method}

Participants. The participants were eight right-handed undergraduate students from Carnegie Mellon University, six male and 2 female, all native speakers of English. All participants gave written, informed consent according to guidelines approved by the University of Pittsburgh and the Carnegie Mellon Institutional Review Boards. Participants were paid for their participation.

Materials. The experimental stimuli consisted of paragraphs adapted from naturally occurring expository texts. Each paragraph was rewritten in a way that it represented a complete text on its own, "a coherent piece of writing exhibiting both structure and texture..." (Davies 1995: 94). All sentences in each paragraph were equated for approximately the same number of words, ranging from 19 to 21 , and also equated for number of characters, ranging from 110 to 130 .

The main idea of each paragraph was identified on the basis of Cunningham and Moore's (1986) definition of a main idea pertaining to the thesis sentence: "The single sentence in a paragraph or passage which tells most completely what the paragraph or passage as a whole states or is about" (p.7). The two supporting sentences in each paragraph presented details and information which illustrated, exemplified or gave support to the main point.

In the topic first condition, the first sentence introduced the theme of the paragraph and the following two sentences presented supporting arguments and details related to the main idea, being easily integrated into one uniform whole as shown in Table 1. In the topic last condition, the supporting arguments and details were presented in the first two sentences making it difficult to integrate them before reading the last sentence, which made the main idea of the paragraph explicit. Two versions of the experimental task were developed. In each version the paragraphs contained the same sentences. The two versions were different in that the location of the topic sentences changed from the first position to the final position and visa versa. In this way each paragraph occurred under each of the two conditions: Topic first and Topic last. Each participant saw only one of the two versions of each paragraph. After reading each paragraph, participants answered true/false probe questions about the thematic information presented (see Table 1 below). 
Now the rest of the world is discovering the power of olive oil, the most versatile fruit juice ever squeezed. (Topic Sentence)

Cosmetics are based on it, diamonds polished with it, and you can also burn it, and lubricate squeaky hinges with it. (First Support Sentence)

It is loaded with vitamin $\mathrm{E}$, it has no cholesterol, and people who eat it have the lowest rate of heart disease. (Second Support Sentence)

Olive oil can be used for many different purposes such as polishing diamonds and preventing heart disease. True or false? (Probe)

Table 1: Sample paragraph.

Procedure. Participants were randomly assigned to the two versions of the experiment. No participant read the same paragraph more than once. Order of presentation of the paragraphs was randomized to minimize practice effects.

As participants were being scanned, they read each paragraph, which was presented word by word in the center of the screen. The duration for which each word was presented was a function of the word's length to accommodate word encoding processes. The total duration of presentation of all the sentences was the same $(8000 \mathrm{~ms})$. A 10.5-second fixation period, during which an " $\mathrm{X}$ " was presented at the center of the screen, was introduced after the presentation of each sentence in order to allow the hemodynamic response to begin to decay before the next sentence appeared. This design made it possible to measure the brain activation associated with the processing of each sentence. However, it does make for an atypical discourse reading paradigm and, therefore, makes it difficult to study discourse processing in the typical manner. Studying discourse processes with fMRI is extremely difficult. The procedures employed are somewhat unorthodox but this is a first attempt at exploring these types of processes. It is hoped that based on this study and others the methodology used for fMRI studies of discourse will be greatly improved. 
After reading each paragraph, participants answered true or false to whether a probe statement represented the main point in the paragraph. The probe questions contained details from each of the three sentences of the paragraph in order to encourage participants to generate a complete text representation. A probe deadline procedure was used and, on the basis of the results in a behavioral pilot study, participants had a maximum of 7 seconds to respond to the probe, after which it disappeared from the screen.

Each participant read twelve paragraphs, six in which the topic sentence was paragraph initial and six in which it was paragraph final. Although the number of trials per condition was not large, it was found to yield significant activation within the regions of interest. However, the number of trials may have caused "real" activation to not be detected due to low signal to noise. Because the goal of the study was to determine if there are processing differences related to the location of the topic sentence within temporal cortex, the current design was thought to be sufficient as a baseline experiment with future studies being planned based upon the current findings.

Four 24 second fixation periods (again, an " $\mathrm{X}$ " centered on the screen) were placed at the beginning, end, and at the two trisection points of the study, to obtain a baseline measure of activation.

Data Acquisition. Functional data were acquired in seven contiguous oblique axial slices situated in order to maximize coverage of the language processing regions (primarily Broca's and Wernicke's areas). The scanning was conducted on a 1.5T General Electric Signa scanner, with a TR $=1500$ $\mathrm{ms}, \mathrm{TE}=50 \mathrm{~ms}$, flip angle $=90^{\circ}, \mathrm{FOV}=40 \times 20 \mathrm{~cm}$, matrix size $=128 \times 64$ voxels, and $1 \mathrm{~mm}$ gap, resulting in a voxel size of $3.125 \times 3.125 \times 5 \mathrm{~mm}$. The slice prescription was set so that the posterior, superior temporal cortex and the inferior frontal gyrus (primarily the superior portion) were adequately covered. Scanning was synchronized with stimulus presentation, the acquisition of the first slice occurring at the onset of each sentence presentation.

For anatomical localization, 3D SPGR structural images were acquired with the following parameters: 124 slices $(1.5 \mathrm{~mm}$ thick), TR=25 ms, 
$\mathrm{TE}=4 \mathrm{~ms}$, flip angle $=40 \mathrm{o}$, and FOV $=24 \mathrm{~cm}$. Functional maps were coregistered with the corresponding structural images.

Anatomical Regions of Interest (ROI). To compare the amount of activation in a given area between the two experimental conditions, anatomically-defined ROIs were drawn for each participant using the parcellation scheme described by Rademacher, Galaburda, Kennedy, Filipek, and Caviness (1992) and further refined by Caviness, Meyer, Makris, and Kennedy (1996). The schematic drawing in Figure 1 below displays most of the ROIs that were examined. This method uses limiting sulci and anatomically landmarked coronal planes to segment cortical regions and has been shown to provide more accurate anatomical localization than does morphing all participants' brains into a common space (NietoCastanon et al 2003).

A staff research assistant defined the ROIs after extensive training on the Rademacher/Caviness parcellation scheme. The anatomical information in the structural images was displayed in the three orthogonal planes simultaneously and the ROIs were manually drawn on each functional slice. The inter-rater reliability of this ROI-defining procedure between two trained staff members was evaluated for four ROIs in two participants in another study. The reliability measure was obtained by dividing the size of the set of voxels that overlapped between the two raters by the mean of their two set sizes. The resulting eight reliability measures were in the 78$91 \%$ range, with a mean of $84 \%$, as high as the reliability reported by the developers of the parcellation scheme (Just et al 2001).

The primary regions of interest were the inferior frontal gyrus (Broca's area) and the superior temporal gyrus, which includes Wernicke's area. However, data from all cortical areas covered by the seven slices obtained are reported for completeness (see Figure 1 below). The inferior frontal ROI (LIFG) included areas F3t and F3o, referring to the Caviness et al. (1996) nomenclature, or approximately BA 44 and a portion of 45 . The temporal ROI (LT) included the superior (T1a and T1p, BA 22) and middle temporal gyri (T2a, T2p, and TO2; BA 21, and 37). The superior and portions of the middle temporal gyri were combined into one ROI because previous studies of language processing have often found activation centered in the superior temporal sulcus between them (Just et al 2001). The ROIs were drawn separately for the left and right hemispheres. 


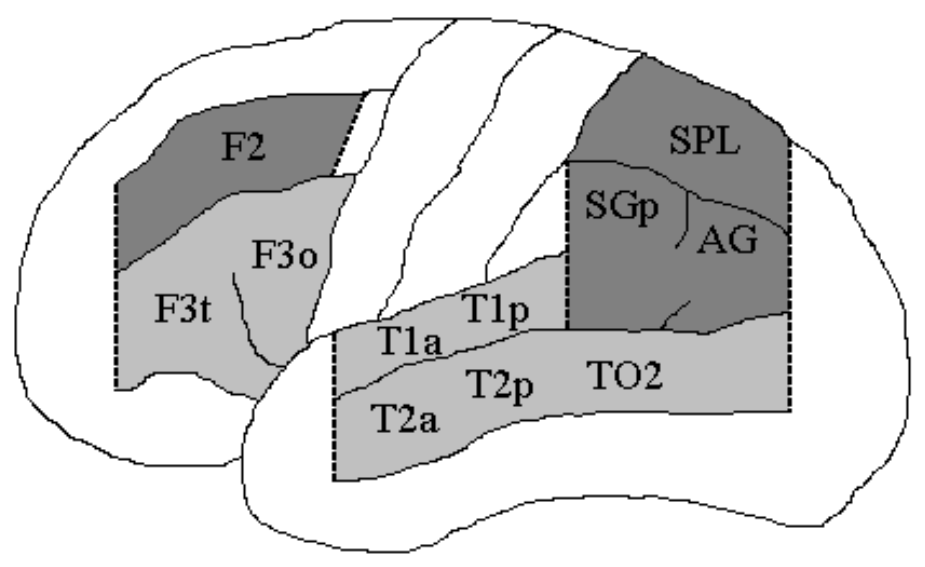

Figure 1: Regions of Interest (ROIs).

Data Analysis. Activation was determined by using FIASCO (Eddy et al., 1996; Lazar et al 2001) to compare the average signal in each voxel during each of the four experimental conditions (topic sentence first, topic sentence last, support sentences first, support sentences last) with the fixation baseline condition using a t-test with a threshold of $t>4$.0. Once t-maps were computed the data analysis quantified the changes in the fMRI-measured signal of the activated voxels by using a dependent measure which takes into account both the volume of activation and the percentage change in signal relative to a baseline level, sum signal intensity (see Keller et al 2003 for details). Sum signal intensity was calculated by summing the percent change in signal intensity for each active voxel within each a priori defined ROI. Group analysis was performed on the sum signal intensity measures obtained from each ROI. A 2x2x2 within-subjects ANOVA with hemisphere (left versus right), sentence type (topic versus support ${ }^{1}$ ) and sentence location (first versus last) was performed for each ROI.

1. The two support sentences were averaged to generate one condition. 


\section{Results}

Behavioral Results. The reaction time and error rate related to the comprehension probe did not differ between conditions, as shown in Figure 2 below.

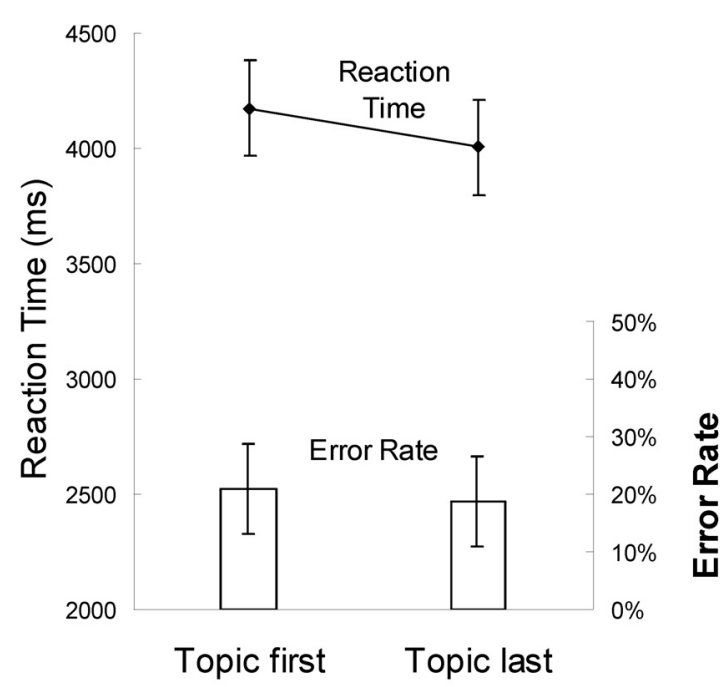

Figure 2: Reaction time to the comprehension probe and error rate as a function of topic sentence location.

fMRI Results. There were two main findings. First, the serial position of the topic sentence had a much larger impact on the left hemisphere language regions than on their right homologues, with the left temporal area showing the most significant effect (see Figures 3 and 4). Second, the right temporal region showed more activation to topic sentences than supporting sentences, regardless of their location within the paragraph (see also, Tomitch, Just \& Newman 2004). These findings are reported in more detail below, focusing on the higher-level language processing regions, namely the inferior frontal gyrus (LIFG or Broca's area) and temporal cortex (Wernicke's area). Table 2 below shows the activation levels and centroids of the activation for each ROI. 


\begin{tabular}{|c|c|c|c|c|c|c|c|}
\hline \multirow[b]{2}{*}{ ROI } & \multicolumn{2}{|c|}{ First } & \multicolumn{2}{|c|}{ Last } & \multirow[b]{2}{*}{$\mathrm{x}$} & \multirow[b]{2}{*}{$\mathrm{y}$} & \multirow[b]{2}{*}{$\mathrm{z}$} \\
\hline & Support & Topic & Support & Topic & & & \\
\hline L. Temporal Cortex & 43.51 & 44.71 & 38.75 & 55.88 & 52.5 & 34.12 & 1.4 \\
\hline R. Temporal Cortex & 14.36 & 21.78 & 15.87 & 22.92 & -50.44 & 37.9 & 6.37 \\
\hline L. Inferior Frontal Gyrus & 20.04 & 13.15 & 16.09 & 25.02 & 46.16 & -12.91 & 21.88 \\
\hline R. Inferior Frontal Gyrus & 3.1 & 2.64 & 2.24 & 2.7 & -43.46 & -19.05 & 23.98 \\
\hline L. Parietal Cortex & 6.12 & 6.9 & 7.69 & 8.74 & 38.26 & 59.42 & 18.39 \\
\hline R. Parietal Cortex & 1.92 & 3.18 & 1.2 & 1.61 & -29.95 & 66.3 & 26.97 \\
\hline $\begin{array}{l}\text { L. Dorsolateral Prefrontal } \\
\text { Cortex }\end{array}$ & 1.83 & 1.14 & 1.63 & 2.31 & 39.47 & -34.12 & 23.63 \\
\hline R. Dorsolateral Prefrontal & & & & & & & \\
\hline Cortex & 0.78 & 0.71 & 0.9 & 0.67 & -30.35 & -45.08 & 18.67 \\
\hline L. Frontal Eye Fields & 3.83 & 4.3 & 3.23 & 4.41 & 38.79 & -5.11 & 38.21 \\
\hline R. Frontal Eye Fields & 1.05 & 2 & 2.4 & 1.74 & -44.68 & -8.35 & 35.74 \\
\hline L. Extrastriate & 20.89 & 24.45 & 20.16 & 23.53 & 30.94 & 76.22 & -8.65 \\
\hline R. Extrastriate & 7.93 & 11.1 & 9.84 & 12.72 & -39.52 & 68.92 & -6.06 \\
\hline
\end{tabular}

Table 2: Activation levels (Sum Percent Signal Intensity).
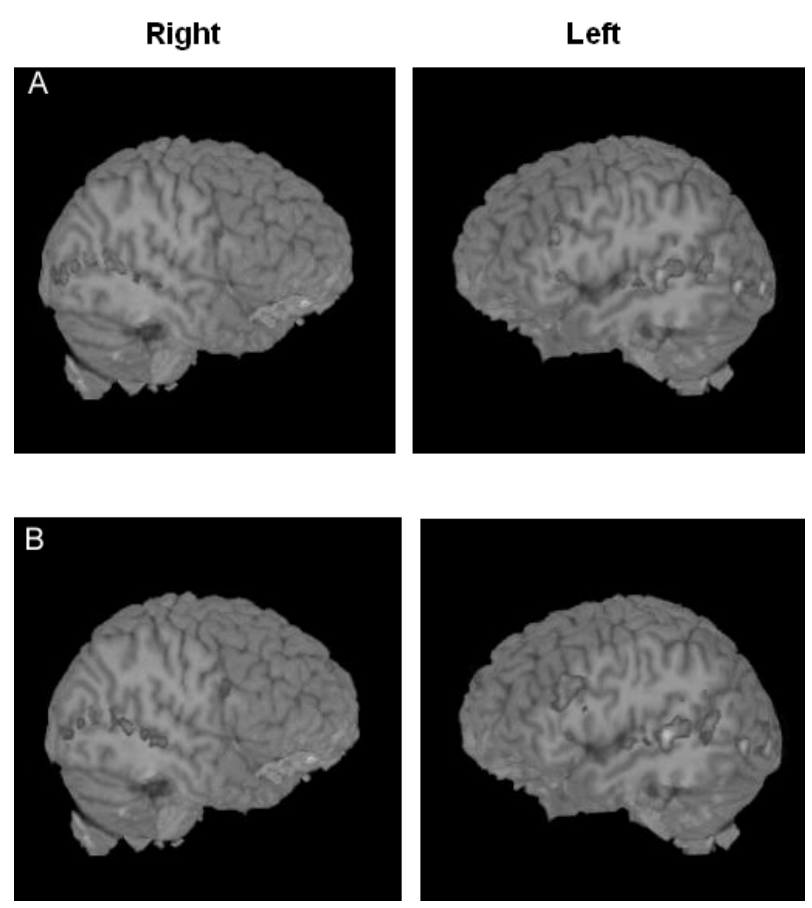

Figure 3: Talairach averaged activation maps (A) Activation elicited by the topic sentence when presented first; B) Activation elicited by the topic sentence when presented last.). 


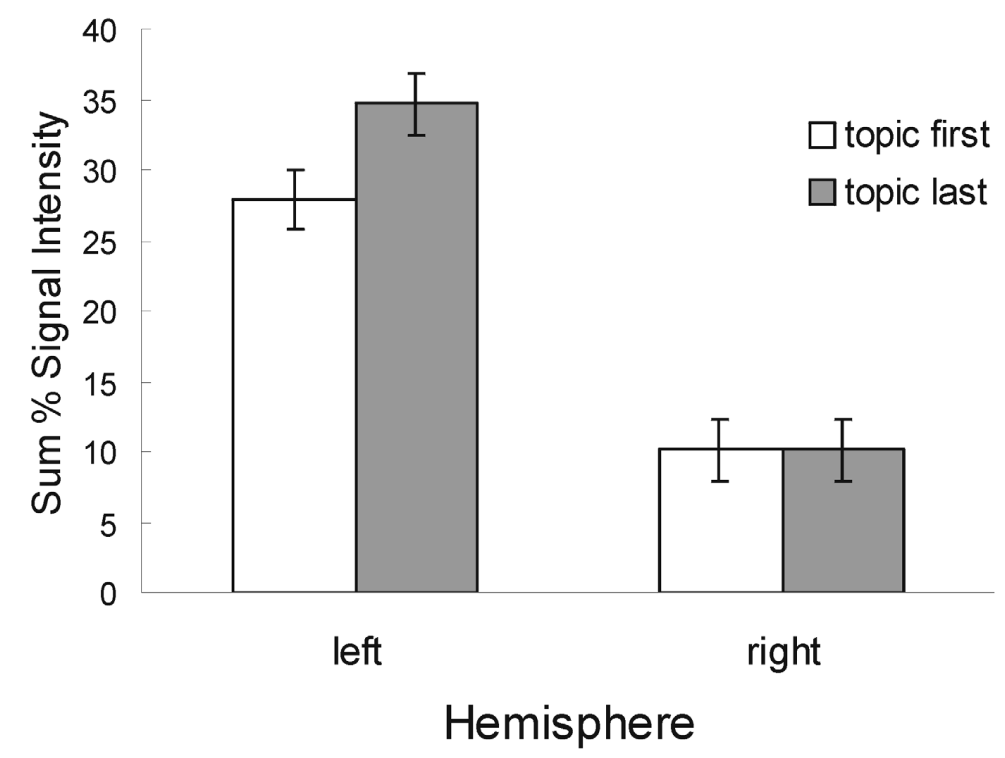

Figure 4: Left Hemisphere versus right hemisphere activation.

Temporal Cortex. An ANOVA with sentence location, sentence type, and hemisphere as within-subject factors revealed main effects of hemisphere, showing that the activation was significantly left lateralized $[\mathrm{F}(1,7)=50.07, \mathrm{p}<0.001]$, and sentence type $[\mathrm{F}(1,7)=10.0, \mathrm{p}<$ $0.05]$, showing that the topic sentence elicited more activation than the supporting sentences (see Figure 5). Post-hoc tests examining each hemisphere showed that both left and right temporal regions revealed a significant effect of sentence type (more activation for topic than support sentences) [left: $\mathrm{F}(1,7)=7.01, \mathrm{p}<0.05$; right: $\mathrm{F}(1,7)=10.18, \mathrm{p}<$ 0.05]. However, as shown in Figure 5, left and right temporal cortex revealed very different responses to topic sentence location. The left temporal region revealed less activation for the topic sentences when it was presented first compared to when presented last $[\mathrm{t}(7)=2.34, \mathrm{p}<$ $0.05]$. Conversely, the support sentences elicited less activation when presented after the topic sentence $[\mathrm{t}(7)=2.1, \mathrm{p}<0.05]$. No such effect was observed in right temporal cortex. 

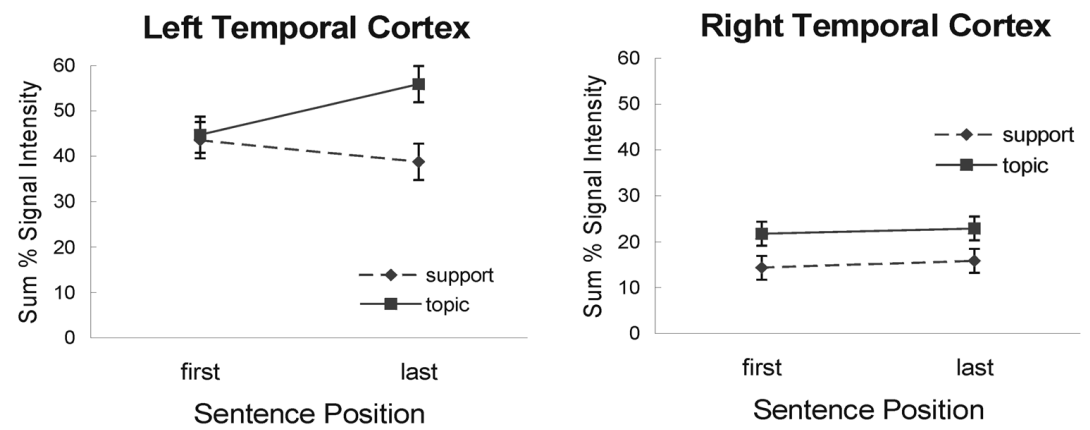

Figure 5: Activation levels observed in the temporal cortex

Inferior Frontal Gyrus. An ANOVA with sentence location, sentence type, and hemisphere as within-subject factors revealed a significant interaction between hemisphere and sentence location $[\mathrm{F}(1,7)=6.41, \mathrm{p}$ $<0.05$ ], with the topic sentence eliciting more activation when presented last and the support sentences eliciting more activation when presented first. Also, like the temporal region, the inferior frontal gyrus also revealed a significant effect of hemisphere $[\mathrm{F}(1,7)=10.41, \mathrm{p}<0.05]$, with the left hemisphere showing more activation than the right. The left IFG revealed a response somewhat similar to that observed in left temporal cortex, as shown in Figure 6. Post-hoc tests examining left and right IFG separately revealed that the effect of sentence location in the left IFG nearly approached significance, while no such difference was observed in the right IFG [left: $\mathrm{F}(1,7)=5.09, \mathrm{p}=0.059$; right: $\mathrm{F}(1,7)=3.3, \mathrm{p}=0.11$. 

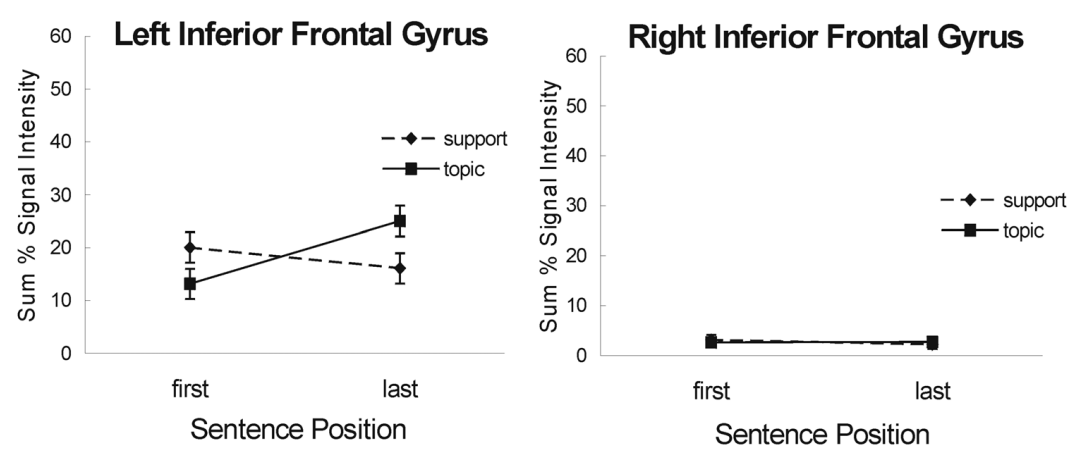

Figure 6: Activation levels observed in the inferior frontal gyrus

\section{Discussion}

The current study is a first attempt at exploring the underlying processes associated with topic identification. The major finding of the current study is the differential response observed in the left and right hemispheres to the location of the topic sentence within a paragraph. The two primary left hemisphere brain regions examined here (temporal cortex and inferior frontal gyrus) responded in similar ways, although to different degrees, to the topic location in this study: greater activation occurred when the topic sentence was in the final position than in the initial position. The right temporal region, on the other hand, was affected only by the sentence type, showing a greater response to topic sentences than support sentences, regardless of their location within the paragraph.

The Structure Building Framework- SBF (Gernsbacher 1990, 1995, 1997) allows for the framing of the current study by making a number of predictions. One such prediction is related to the differential involvement of the "shifting" process in paragraphs whose topic sentence is in the final position. This is because when the topic is in the final position the less coherent is the text, meaning the sentences seem less related which then leads to a greater number of substructures generated within the text representation (i.e., greater "shifting"). Therefore, this increase in the 
amount of "shifting" taking place during the topic last condition would be expected to result in greater activation for the topic last condition compared to the topic first condition. This predicted response was observed in the left temporal region, not the right, as shown in Figure 5. The left temporal region revealed a differential response to the topic location, with the topic sentence eliciting more activation when it was in the final position than when it was in the initial position. In addition, the support sentences showed the opposite effect: greater activation when they were located in the initial position compared to when they were in the final position. Thus, while the left hemisphere is involved in comprehension processes at all times, the introduction of coherence gaps increases its processing load. This increased processing load may be a function of an increased need to shift or reorganize the text representation in memory.

The increased involvement of the left hemisphere during the topic last condition appears to be at odds with previous reports in the literature. For example, St George et al (1999), in an fMRI study of semantic integration in reading in which participants read vague and ambiguous paragraphs in the Bransford and Johnson (1972) unlabeled text style, found a different pattern of activation for titled and untitled paragraphs, where titled paragraphs were similar to the topic first condition and untitled paragraphs were similar to the topic last condition here. While the current results revealed greater left hemisphere involvement for the topic last compared to topic first condition, St George and colleagues found a similar effect in the right hemisphere; untitled paragraphs produced higher levels of activation in the right hemisphere than titled paragraphs. Although the two studies appear to be at odds, there are a number of methodological differences that may account for the disparate results. First, the current study requires participants to respond to a comprehension question after reading the paragraph; there is no such requirement in the previous study. Secondly, the topic (title) is always provided in the current study therefore, there is always opportunity to generate a coherent text representation. In the previous study the untitled condition never provides a unifying theme to bring all of the information together making it impossible to generate a coherent representation. Finally, the anatomical regions scanned in the two studies are quite different. The slices acquired in the St. George study covered the middle and inferior temporal cortex and the inferior portion of Broca's area only. The current study covered portions of the middle temporal cortex, the superior temporal-parietal cortex (Wernike's area) and the 
superior portion of Broca's area, neither of which were scanned in the previous study. This difference in the anatomical regions examined is a significant one because these regions have been shown to be involved in different processes, particularly in the left hemisphere. For example, the anterior, inferior portion of Broca's area (BA 45) has been found to be involved in semantic processing (Newman et al 2003; Fiez 1997; Wagner et al 2000) while the posterior, superior portion (BA 44) is more involved in syntactic processing (Dapretto et al 1999; Embick et al 2000; Newman et al 2003). Although there are fewer reports investigating the processing in the right hemisphere, similar differences may be expected. As a result of these methodological differences it is difficult to directly compare the studies and further research is needed to clarify this issue.

The current study seems to suggest a role for the left temporal and inferior frontal region in the shifting process. One possible explanation for the left temporal region's involvement in shifting may be found in the region's involvement in memory processing more generally. Consider the possibility that when reading a text various concepts activate a certain feature space within memory and as incoming information comes in, there is a check to see how much the new concept's feature space overlaps with previous information. If the overlap is above some threshold, then it is possible that it is just added to the current representation. If not, then a "shift" happens and a new, or a more elaborate memory substructure is created. It may be that the left hemisphere is responsible for holding this representation on-line. There are many studies that associate left temporal and inferior frontal cortex to memory functions including semantic memory. For example, the superior portion of the inferior frontal gyrus is thought to become more involved during sentence comprehension when memorydemanding dependencies between elements in a sentence must be established (Fiebach, et al 2004; Cooke et al 2001; Fiebach et al 2001). In the current study, when the topic is in the final position similar memorydemanding dependencies must be established in order to relate the sentences within the paragraph.

In an fMRI study of the cognitive process of mapping (' $\ldots$ identify... recurring concepts and have a means for interrelating them', p.3), Robertson et al (2000) gave participants two sets of narrative paragraphs. In one set, the sentences contained the definite article 'the' modifying nouns. Another set of sentences contained the indefinite article 'a'. Robertson et al (2000) 
and Gernsbacher and Robertson (1992) suggested that the definite article 'the' serves as a cue to map a representation of the current input and found the involvement of the right hemisphere. One of the consequences of having the topic sentence in the final position is that the preceding supporting sentences have unresolved anaphors. For example, the support sentence "It is loaded with vitamin E, it has no cholesterol, and people who eat it have the lowest rate of heart disease" does not state what "it" refers to. In contrast, when the topic sentence is in the initial position, such as "Now the rest of the world is discovering the power of olive oil, the most versatile fruit juice ever squeezed", the topic of the paragraph is explicitly stated (olive oil in this case), facilitating the resolution of anaphors in the subsequent support sentences (it-olive oil). Therefore, in the current experiment, the mapping process may be expected to be cued more often when the topic sentence is located in the final position because only then can the recurring concepts be identified and interrelated.

The results presented here do suggest significant processing differences between the left and right hemisphere during text processing. According to the coarse coding hypothesis the left hemisphere activates a small number of representations to a high degree making it ideal for working/short-term memory language functions. Also, previous studies at the word and sentence level have shown that the left hemisphere is involved in memory intensive language processing such as semantic and syntactic processing. These processes occur at both the sentence and discourse level. However, because the left hemisphere is so involved in memory it may be that the text representation is stored/processed in the left hemisphere. If this is the case then its increased involvement when the topic is located at the end of a paragraph would be due to the reorganization or even the generation of this memory structure.

The right hemisphere, on the other hand, is thought to activate a broad range of concepts at a weak level making it ideal for inference generation that connects events and details within a text. The fact that it is equally involved during the processing of the topic sentence regardless of its location may be a result of different processes. For example, it may be that when the topic is first the right hemisphere is involved in laying the foundation of the text representation and beginning to weakly activate a number of concepts related to the topic. Conversely, when the topic is in the final position the right hemisphere may be involved in the mapping 
process of SBF in order to perform anaphor resolution and to begin to relate the information that was presented previous to the topic. This would coincide with the shifting processes taking place in the left hemisphere that are reorganizing/generating a memory structure. Knowledge of how to relate the new information with the old is needed before the text representation can be edited and this knowledge may be generated by the right hemisphere.

\section{Conclusions}

Discourse comprehension is a collaborative effort involving both the left and right hemisphere language areas, as these fMRI results show. The systematic activation observed in both hemispheres in our study suggests that the two hemispheres work in an integrated manner, each being differentially responsible for various aspects of language processing (Mazoyer et al 1993), but working together to achieve the more global role of discourse comprehension. The integrated manner in which the biology appears to execute discourse processing also suggests that the underlying cognitive processes are non-modular. For example, the data presented here suggests that the foundation is not formed irrespective of the content of the initial sentence and that the lexical/semantic processing of each individual sentence in a text dynamically influences the text representation.

Recebido em novembro de 2005 Aprovado em outubro de 2007 E-mail: leda@cce.ufsc.br

\section{REFERENCES}

Bavelier, D.; Corina, D.; Jezzard, P.; Padmanabhan, S.; Clark, V. P.; Karni, A.; Prinster, A.; Braun, A.; Lalwani, A.; Rauschecker, J. P.; Turner, R. \& Neville, H. 1997. Sentence reading: A functional MRI study at 4 Tesla. Journal of Cognitive Neuroscience 9: 664-686.

BeEman, M. 1993. Semantic processing in the right hemisphere may contribute to drawing inferences during comprehension. Brain and Language, 44: 80-120. 
. 1998. Coarse semantic coding and discourse comprehension. In: M. Beeman \& C. Chiarello, (Eds.), Right hemisphere language comprehension: Perspectives from cognitive neuroscience, pp. 255-284. Mahwah, NJ: Lawrence Erlbaum Associates.

Beeman, M.; Friedman, R. B.; Grafman, J.; Perez, E.; Diamond, S. \& LindSAY, M. B. 1994. Summation priming and coarse coding in the right hemisphere. Journal of Cognitive Neuroscience, 6: 26-45.

BINDER, J. R. 1997. Neuroanatomy of language processing studied with functional MRI. Clinical Neuroscience, 4: 87-94.

Bottini, G; Corcoran, R.; Sterzi, R.; Paulesu, E.; Schenone, P.; Scarpa, $\mathrm{P}$, et al. 1994. The role of the right hemisphere in the interpretation of figurative aspects of language. A positron emission t omography activation study. Brain, 117: 1241-53.

Bransford, J. D. \& Johnson, M. K. 1972. Contextual prerequisites for understanding: some investigations of comprehension and recall. Journal of Verbal Learning and Verbal Behavior, 11: 717-726.

Brownell, H. \& Martino, G. 1998. Deficits in inference and social cognition: The effects of right hemisphere brain damage on discourse. In: M. Beeman \& C. Chiarello (Eds.), Right hemisphere language comprehension: Perspectives from cognitive neuroscience (pp. 309-328). Mahwah, NJ: Erlbaum.

Brunswick, N.; Mccrory, E.; Price, C. J. \& Frith, C. D. 1999. Explicit and implicit processing of words and pseudowords by adult developmental dyslexics. A search for Wernicke's Wortschatz? Brain, 122: 1901-1917.

Caplan, D.; Alpert, N. \& Waters, G. 1999. PET studies of syntactic processing with auditory sentence presentation. NeuroImage, 9: 343-351. Caviness, V. S. Jr.; Meyer, J.; Makris, N. \& Kennedy, D. N. 1996. MRIbased topographic parcellation of human neocortex: An anatomically specified method with estimate of reliability. Journal of Cognitive Neuroscience, 8: 566-87.

Cooke, A.; Zurif, E. B.; Devita, C.; Alsop, D.; Koenig, P.; Detre, J.; Gee, J.; Pinango, M.; Balogh, J. \& Grossman, M. 2001. Neural basis for sentence comprehension: Grammatical and short-term memory components. Human Brain Mapping, 15: 80-94.

Cunningham, J.W. \& Moore, D.W. 1986. The confused world of main idea. In: J.F. Baumann (Ed.), Teaching main idea comprehension. Newark, DEL: International Reading Association. 
Dapretto, M. \& Bookheimer, S. 1999. Form and content: Dissociating syntax and semantics in sentence comprehension. Neuron, 24: 427-432.

DaviEs, Florence. 1995. Introducing reading. UK: Penguin Books.

Dehaene, S.; Dupoux, E.; Mehler, J.; Cohen, L.; Paulesu, E.; Perani, D.; Van de Moortele, P-F.; Lehericy, S. \& Lebihan, D. 1997. Anatomical variablity in the cortical representation of first and second language. NeuroReport, 8: 3809-3815.

Eddy, W.; Fitzgerald, M.; Genovese, C.; Mockus, A. \& Noll, D. 1996. Functional imaging analysis software - computational olio. In: Proceedings in Computational Statistics. Physica-Verlag, Heidelberg, pp. 39-49.

Embick, D.; Marantz, A.; Miyashita, Y. et al. 2000. A syntactic specialization for Broca's area. Proceedings of the National Academy of Science. USA, 97,6150-6154.

Fiebach, C. J.; Schlesewsky, M. \& Friederici, A. D. 2001. Syntactic working memory and the establishment of filler-gap dependencies: Insights from ERPs and fMRI. Journal of Psycholinguistic Research, 30: 321-338.

Fiebach, C.J.; Vos, S.H. \& Friederici, A.D. 2004. Neural correlates of syntactic ambiguity in sentence comprehension for low and high span readers. Journal of Cognitive Neuroscience, 16: 1562-1575.

Fiez, J. \& Petersen, S. E. 1998. Neuroimaging studies of word reading. Proceedings of the National Academy of Science, USA, 95, 914-921.

Gernsbacher, M. A. 1990. Language comprehension as structure building. Hillsdale, NJ: Lawrence Erlbaum Associates.

Gernsbacher, M. A. 1995. The Structure Building Framework: What it is, what it might also be, and why. In: B. K. Britton, \& A. C. Graesser, (Eds.), Models of text understanding (pp. 289-311). Hillsdale, NJ: Erlbaum.

Gernsbacher, M. A. 1997. Two decades of structure building. Discourse Processes, 23: 265-304.

Gernsbacher, M. A. \& Robertson, R. R. W. 1992. Knowledge activation versus sentence mapping when representing fictional characters' emotional states. Language and Cognitive Processes, 7: 353-371.

Hagoort, P.; Indegrey, P.; Brown, C.; Herzog, H.; Steinmetz, H. \& Seitz, R. 1999. The neural circuitry involved in the reading of German words and pseudowords: a PET study. Journal of Cognitive Neuroscience, 11: 383-398. 
FIEZ, J. A. 1997. Phonology, semantics, and the role of the left inferior prefrontal cortex. Human Brain Mapping, 5: 79-83.

Just, M. A.; Carpenter, P. A.; Keller, T. A.; Eddy, W. F. \& Thulborn, K. R. 1996. Brain activation modulated by sentence comprehension. Science, 274: 114-116.

Just, M. A.; Carpenter, P. A.; Maguire, M., Diwadkar, V. \& Mcmains, S. 2001. Mental rotation of objects retrieved from memory: an fMRI study of spatial processing. Journal of Experimental Psychology: General, 130: 493-504.

Keller, T. A.; Carpenter, P. A. \& Just, M. A. 2001. The neural bases of sentence comprehension: an fMRI examination of syntactic and lexical processing. Cerebral Cortex, 11:223-237

Keller, T. A.; Carpenter, P. A. \& Just, M. A. 2003. Brain imaging of tongue-twister sentence comprehension: Twisting the tongue and the brain. Brain and Language, 84: 189-203.

Kintsch, W. \& Van Dijk, T. A. 1978. Toward a model of text comprehension and production. Psychological Review, 85: 363-394.

Lazar, N. A.; Eddy, W. F.; Genovese, C. R. \& Welling, J. S. 2001. Statistical Issues in fMRI for Brain Imaging. International Statistical Review, 69: 105-27.

Mason, R. A. \& Just, M. A. 2004. How the brain processes causal inferences in text: A multiple process theory of the function of the language network in both hemispheres. Psychological Science, 15: 1-7.

Mazoyer, B.M.; Tzourio, N.; Frak, V.; Syrota, A.; Murayama, N.; Levrier, O.; Salamon, G.; Dehaene, S.; Cohen, L. \& Mehler, J. 1993. The cortical representation of speech. Journal of Cognitive Neuroscience, 5(4): 467-479.

Michael, E. B.; Keller, T. A.; Carpenter, P. A. \& Just, M. A. 2001. An fMRI investigation of sentence comprehension by eye and by ear: Modality fingerprints on cognitive processes. Human Brain Mapping, 13: 239-252.

Newman, S. D.; Just, M. A.; Keller, T. A.; Roth, J. \& Carpenter, P. A. 2003. Differential effects of syntactic and semantic processing on the subregions of Broca's area. Cognitive Brain Research, 4: 297-307.

Nichelli, P.; Grafman, J.; Pietrini, P.; Clark, K.; Lee, K. Y. \& Miletich, R. 1995. Where the brain appreciates themoral of a story. Neuroreport, 6: 2309-2313. 
Nieto-Castanon, A.; Ghosh, S.S.; Tourville, J.A. \& Guenther, F. H. 2003. Region of interest based analysis of functional imaging data, NeuroImage, 19: 1303-1316.

Petersen, S. E.; Fox, P. T.; Posner, M. I.; Mintun, M. \& Raichle, M. E. 1989. Positron emission tomographic studies of the processing of single words. Journal of Cognitive Neuroscience, 1: 153-170.

Petersen, S. E.; Fox, P. T.; Snyder, A. Z. \& Raichle, M. E. 1990. Activation of extrastriate and frontal cortical areas by visual words and word-like stimuli. Science, 249: 1041-1044.

Pugh, K.; Mencl, E. W.; Shaywitz, B. A.; Shaywitz, S. E.; Fulbright, R. K.; Skudlarski, P.; Constable, R. T.; Marchione, K.; Jenner A.R.; Shankweiler, D. P.; Katz, L.; Fletcher, J.; Lacadie, C. \& Gore, J. C. 2000. The angular gyrus in developmental dyslexia: Task-specific differences in functional connectivity in posterior cortex. Psychological Science, 11: 51-56.

Pugh, K.; Shaywitz, B.; Constable, T.; Shaywitz, S.; Skudlarski, P.; Fullbright, R.; Bronen, R.; Shankweiler, D.; Katz, L.; Fletcher, J. \& Gore, J. 1996. Cerebral organization of component processes in reading. Brain, 119: 1221-1238.

Rademacher, J.; Galaburda, A. M.; Kennedy, D. N.; Flilipek, P. A. \& CAviness, V. S. 1992. Human cerebral cortex: localization, parcellation, and morphometry with magnetic resonance imaging. Journal of Cognitive Neuroscience, 4: 352-74.

Robertson, D. A.; Gernsbacher, M. A.; Guidotti, S. J.; Robertson, R. R. W.; Irwin, W.; Mock, B. J. \& Campana, M. E. 2000. Functional neuroanatomy of the cognitive process of mapping during discourse comprehension. Psychological Science, 11: 255-260.

Schlosser, M. J.; Aoyagi, N.; Fulbright, R. K.; Gore, J. C. \& Mccarthy, G. 1998. Functional MRI of auditory comprehension. Human Brain Mapping, 6: 1-13.

Shaywitz, B. A.; Pugh, K. R.; Jenner, A. R.; Fullbright, R. K.; Fletcher, J. M.; Gore, J. C. \& ShaYwitz, S. E. 2000. The neurobiology of reading and reading disability (Dyslexia). In: M.L. Kamil, P.B. Mosenthal, P.D. Pearson \& R. Barr (Eds.), Handbook of Reading Research, Vol. III. Mahwah, N.J.: Lawrence Erlbaum Associates.

St George, M.; Kutas, M.; Martinez, A. \& Sereno, M. I. 1999 Semantic integration in reading: engagement of the right hemisphere during discourse processing. Brain, 122: 1317-25. 
Stromswold, K.; Caplan, D.; Alpert, N. \& Rauch, S. 1996. Localization of syntactic comprehension by positron emission tomography. Brain and Language, 52: 452-473.

Tomitch, L. M. B.; Just, M. A. \& Newman, S. 2004. A neuroimagem funcional na investigação do processo de leitura. In: Rodrigues, C. \& Tomitch, L.M.B (orgs.). Linguagem e cérebro humano: contribuições multidisciplinares. Porto Alegre, RS: ARTMED Editora.

VAn Dijk, T. A. \& KInTSCH, W. 1983. Strategies of discourse comprehension. New York: Academic Press.

Wagner, A; KoustaAl, W.; Maril, A. et al. 2000. Semantic repetition priming for verbal and pictorial knowledge. Journal of Cognitive Neuroscience, 9: 714-26.

Waldie, K. \& Mosley, J. 2000. Hemispheric specialization for reading source. Brain and Language, 75: 108-122. 